\title{
Epidemiological characteristics of suicide cases in Rafsanjan from 2004 to 2009: the roles of family disputes and unemployment
}

\author{
Rezaeian M, PhD * \\ Professor, Dept. of Social Medicine, Medical School, Occupational Environmental Research Center, Rafsanjan \\ University of Medical Sciences, Rafsanjan, Iran.
}

\begin{abstract}
:
Received: May 2012, Accepted: August 2012

Background: Suicide can be defined as an intentional act of self harm that leads to death. The aim of the present study was to determine the epidemiological characteristics of suicide cases which were recorded by Rafsanjan Legal Medical Organization from 2004 to 2009.

Materials and Methods: This descriptive study was carried out in the year 2010 in Rafsanjan County of Kerman Province which is located in Southeast of Iran. Suicide data were gathered by applying a checklist in which gender, age, method of committing suicide as well as cause and the year of the event were recorded.

Results: During the six years of our investigation, 20 cases of suicide were recorded. The mean age were $27.92 \pm 6.77$ and $29.14 \pm 10.38$ years for males and females, respectively. There were 13 $(65 \%)$ males among the cases. Poison ingestion in $7(35 \%)$ cases was the highest most frequent applied method of suicide. Family disputes in $16(80 \%)$ cases and unemployment along with addiction in $4(20 \%)$ cases were reported as the causes of suicide.

Conclusion: Although it seems that suicide occurs less often in Rafsanjan, the possibility of underenumeration and under-reporting of it must also be taken into account. In addition, a comprehensive prevention plan should be designed and implemented in order to tackle the root causes of suicide i.e. family disputes, unemployment and addiction. Meanwhile, easy access to the most prominent method of suicide i.e. organophosphate poison and similar substances should be restricted.
\end{abstract}

Keywords: Suicide, Epidemiology, Disputes, Unemployment

\section{Introduction}

More than 1 million people commit suicide each year worldwide [1]. Therefore, this phenomenon is estimated to be the 13th leading cause of death all around the world. Evidence suggests that almost half of all suicides occur in three countries i.e. China, India, and Japan [2]. Further evidence indicates that during recent decades suicide rates are growing within developing countries especially the Middle Eastern countries [3, 4]. In Iran, it is shown that each day nearly 10 cases of suicide occur and people in western provinces of Iran are more prone to commit suicide than other provinces [5]. Since almost in all countries suicide is not culturally accepted one of the most important issues in suicide studies is definition of this phenomenon. Suicide conceptually can be defined as "an act with a fatal outcome, that is deliberately initiated and performed by the deceased person itself, in the knowledge or expectation of its fatal outcome, the outcome being considered by

\footnotetext{
* Corresponding author: Mohsen Rezaeian, School of Medicine, Occupational Environmental Reseaech Center, Rafsanjan University of Medical Sciences, Rafsanjan, Iran.

E-mail: moeygme2@yahoo.co.uk
} 
the actor as instrumental in bringing about desired changes in consciousness and/or social conditions" [6]. More simply suicide can also be defined as "deliberate act of self harm leading to death" [7]. There are other conceptual definitions of suicide, but how we need to define suicide, as a measurable and operational phenomenon for investigation, is the most important issue. In order to define an operational definition of suicide, it is necessary to determine how suicide is officially recorded. In many countries the official process of recording suicide is through the judicial system [8, 9]. For instance, in the USA, "a coroner or medical examiner usually determines whether a death is a suicide or not and then records that decision on the death certificate" [10]. In the UK, also when it is suspected that the death is due to unnatural causes, it must be reported to the coroner, who may order a post-mortem examination and may hold an inquest. As soon as the cause of death is established, the coroner signs a death certificate [11]. Clearly, under-enumeration and under-reporting might happen in all these procedures.

In Iran there are usually two sources for suicide data. The first source is related to death certificate which is reported by the Iranian Ministry of Health, Treatment and Medical Education. The second source relates to only those deaths that occur due to unnatural causes and refer to judiciary system. These deaths are further investigated by Legal Medical Organization and might be recorded as suicide. Although it seems that Iranian Ministry of Health data have more coverage than the Legal Medical Organization data, both sources of data have suffered from under-enumeration and underreporting. Furthermore, Iranian Ministry of Health data still need to be improved and cover all provinces of Iran [5].
Having considered the above methodological issues in accounting the number of suicide, the aim of the present article was to determine the epidemiological characteristics of suicide cases which were recorded by Rafsanjan Legal Medical Organization from 2004 to 2009.

\section{Materials and Methods}

This descriptive study was carried out in the year 2010 within Rafsanjan County. It should be noted that Rafsanjan County is a county in Kerman province which is located in Southeast of Iran (Figure 1). The county's population based on the 2006 census was 291,417 and the county is famous all over the world for its pistachio cultivation. In the year 2003 Rafsanjan was the largest producer of pistachio in Kerman province with 38151 pistachio producers and sharing $43.7 \%$ of all pistachio production [12].

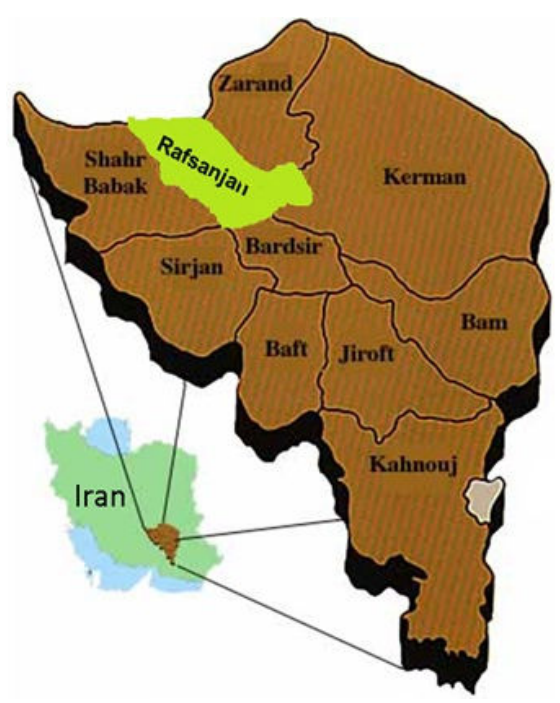

Figure1: The geographical location of Rafsanjan County in Kerman province of Iran

Suicide data were obtained from Rafsanjan Legal Medical Organization applying a checklist in which gender, age, method of committing suicide plus cause and the year 
of the event were recorded. The checklists were completed for all suicides that happened from 2004 to 2009. Unfortunately, no reliable data had been recorded in Rafsanjan Legal Medical Organization before 2004. Data on the completed checklists were entered into SPSS (version 18) and were analyzed using Fisher's Exact and Student t-tests. It should also be mentioned that the methods of the study were approved by Rafsanjan University of Medical Sciences Ethics Committee.

\section{Results}

During six years of investigation 20 cases of suicide had been recorded in Rafsanjan Legal Medical Organization. Figure 2 depicts the number of suicidal cases per year. The mean of age were $27.92 \pm 6.77$ and $29.14 \pm 10.38$ years for men and women, respectively. Student t-test did not reveal any significant difference between these values.

There were $13(65 \%)$ men among the cases. Family disputes in 16 (80\%) cases and unemployment plus addiction in $4(20 \%)$ cases were recorded as the causes of suicide. Poison ingestion in $7(35 \%)$ cases and falling in $1(5 \%)$ case were the most and the least frequent applied methods of suicide.

The distribution of causes and methods of suicide based on the gender of the cases are presented in table 1. Based on this table, those four cases who committed suicide as a result of unemployment plus addiction were men whilst the nine remaining men and all seven women had committed suicide as a result of family disputes. Furthermore, two out of seven female cases had committed suicide by applying self-immolation method whilst five men plus two women had committed suicide by applying poison ingestion method.

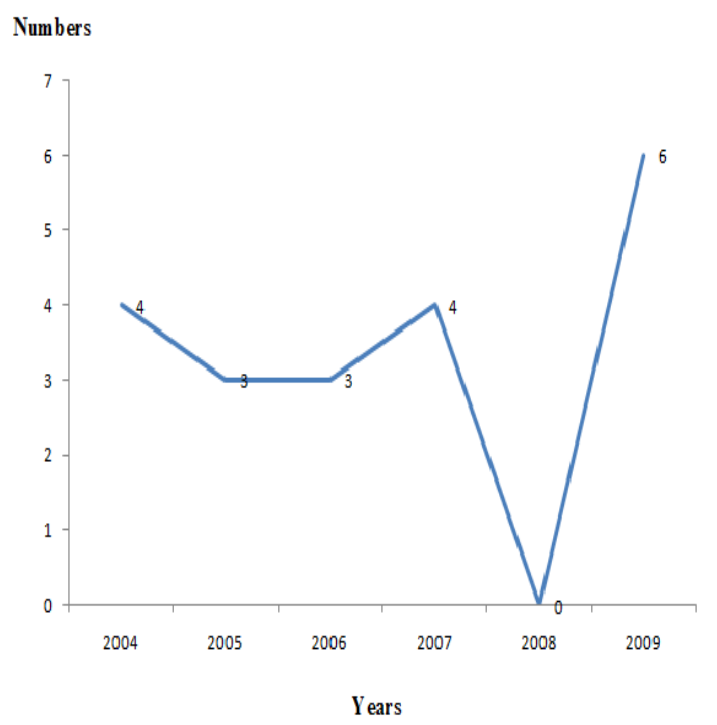

Figure 2: The number of suicidal cases per year (2004-2009)

Table 1: Frequency distribution of cases based on gender, causes and methods of suicide

\begin{tabular}{|c|c|c|c|c|c|}
\hline \multirow{3}{*}{ Variables } & \multicolumn{4}{|c|}{ Gender } & \multirow{3}{*}{ Statistical tests } \\
\hline & \multicolumn{2}{|c|}{ Men } & \multicolumn{2}{|c|}{ Women } & \\
\hline & $\mathbf{N}$ & $\%$ & $\mathbf{N}$ & $\%$ & \\
\hline $\begin{array}{l}\text { Cause } \\
\text { - Family disputes } \\
\text { - Unemployment }\end{array}$ & $\begin{array}{l}9 \\
4\end{array}$ & $\begin{array}{l}69.2 \\
30.8\end{array}$ & $\begin{array}{l}7 \\
0\end{array}$ & $\begin{array}{c}100 \\
0\end{array}$ & $\begin{array}{c}\text { Fisher's Exact Test } \\
\qquad \underline{P=0.249}\end{array}$ \\
\hline $\begin{array}{l}\text { Methods } \\
\text { - Drug ingestion } \\
\text { - Hanging } \\
\text { - Poison ingestion } \\
\text { - Self-immolation } \\
\text { - Falling } \\
\text { - Unknown }\end{array}$ & $\begin{array}{l}3 \\
2 \\
5 \\
0 \\
0 \\
3\end{array}$ & $\begin{array}{c}23.1 \\
15.4 \\
38.5 \\
0 \\
0 \\
23.1\end{array}$ & $\begin{array}{l}0 \\
1 \\
2 \\
2 \\
1 \\
1\end{array}$ & $\begin{array}{c}0 \\
14.3 \\
28.6 \\
28.6 \\
14.3 \\
14.3\end{array}$ & Not valid \\
\hline
\end{tabular}




\section{Discussion}

From 2004 to 2009 only 20 cases of suicide were recorded in Rafsanjan Legal Medical Organization. Although this might mean that suicide event could be considered as having a low frequency within Rafsanjan, it would not be possible to rule out any underenumeration and under-reporting. As it has already been discussed, Legal Medical Organization in Iran only recorded those suicides that refer to judiciary system and these cases do not contain all suicides that happen in Iran.

Moreover, evidence also suggests that due to stigma associated with suicide there are under-enumeration and under-reporting in any existing data especially within developing countries with religious backgrounds [13-16]. Therefore, as a religious county, it would also be possible that we further encounter with underenumeration and under-reporting of suicide cases in Rafsanjan, the extent of which is very difficult to determine.

Our results highlighted that $16(80 \%)$ cases, had committed suicide as a result of family disputes. A family dispute is a common term which might encompass several scenarios including dispute with the spouse, dispute with parents, disputes in love affairs, etc. Unfortunately a substantial number of studies documented family disputes as one of the most common reasons for committing suicide [17-20]. Therefore, primary prevention plans for suicide must take these important issues into account.

Our results also highlighted that 4 (20\%) cases, all men, had committed suicide as a result of unemployment plus addiction. Although there is evidence to link suicide and unemployment, the case for direct causality has not been established. Furthermore, person-based studies and aggregated studies have produced conflicting results in terms of association between suicide and unemployment in different gender [21-24]. Clearly, more studies are needed to explore the complex interaction between suicide and unemployment. Moreover, since addiction should have an interaction with both unemployment and suicide, further studies should also explore the complex interaction of co-occurring between suicide, unemployment and addiction [25]. As our study has shown this complex interaction happens more likely among men than women. However, the results of other studies have shown that whilst unemployment might be a more important factor among men with suicidal ideation, illicit drug abuse is a more important factor among women with suicidal ideation [26]. Again, primary prevention plans for suicide must take these important issues into account.

Our results also revealed that poison ingestion in $7(35 \%)$ cases is the highest applied methods of suicide. This picture is in accordance with socio-economic status of the county. As it has been already mentioned the county is famous for its pistachio farming and easy access to poison especially organophosphate pesticides is evident (12). It is documented that the $95 \%$ of pesticides used in Rafsanjan are organophosphate pesticides [27]. Similar patterns, i.e. high intentional fatal self-poisoning is also reported by other studies [28-30].

Therefore, suicidal prevention plan in Rafsanjan should also focus on restriction of easy access to such poisons. This could happen by storing such poisons away from homes in a locked storage place [31].

Finally, two female cases in our study had committed suicide using self-immolation methods. Evidence suggests that self-burning mostly occurs in young, married, deprived 
and not well-educated women in India and Middle Eastern countries [32-35]. A recent study showed that the case fatality rate of self-immolation could be up to 70 percent [36]. Again, more studies are needed to shed light on epidemiology of self-immolation in the affected areas including Rafsanjan.

\section{Conclusion}

Although it seems that suicide occurs in a low frequency in Rafsanjan, the possibility of under-enumeration and under-reporting of it must also be taken into account. Furthermore, a comprehensive prevention plan should be designed and implemented in order to tackle the root causes of suicide i.e. family disputes, unemployment plus addiction. Meanwhile, easy access to the most prominent method of suicide i.e. organophosphate poison should also be restricted.

\section{Acknowledgment}

Author thanks all people who helped with the different parts of this study, in particular data collection process.

\section{Conflict of interest: Non declared}

\section{References}

1. World Health Organisation. World health report on violence and health. Geneva: WHO 2002.

2. Bailey RK, Patel TC, Avenido J, Patel M, Jaleel M, Barker NC, et al. Suicide: current trends. J Natl Med Assoc 2011; 103(7):614-7.

3. Rezaeian M. Suicide among young Middle Eastern Muslim females. Crisis 2010; 31(1):36-42.

4. Afifi M. Adolescent suicide in the Middle East: Ostrich head in sand. Bull World Health Organ 2006; 84(10): 840

5. Rezaeian M (2009). Epidemiology of Suicide. Arak: Nevisandeh Publications. [Persian]
6. Retterstol N (1993). Suicide A European perspective. Cambridge: Cambridge University Press.

7. Amos T, Appleby L (2001) Suicide and deliberate self-harm In Appleby 1, Forshaw DM, Amos T, Barker H. Postgraduate psychiatry: clinical and scientific foundations, London: Arnold,: 347-357.

8. Hawton K, van Heeringen K. Suicide. Lancet 2009; 373(9672):1372-81.

9. Gunnell DJ. The epidemiology of suicide. Int Rev Psychiatry 2000; 12(1): 21-26.

10. Centers for Disease Control (CDC). Operational criteria for determining suicide. MMWR Morb Mortal Wkly Rep 1988; 37(50): 773-4.

11. Farmer R, Miller D, Lawrenson R (1996). Epidemiology and public health medicine. $4^{\text {th }}$ ed. Oxford: Blackwell Science Ltd.

12. Mehrabi Boshrabadi H, Villano R, Fleming E. Production relation and technical inefficiency in pistachio production systems in Kerman province of Iran. Working paper series in agricultural and resource economics 2006; University of New England. http://www.une.edu.au/febl/EconStud/wps.htm.

13. Milner A, De Leo D. Suicide research and prevention in developing countries in Asia and the Pacific. Bull World Health Organ 2010; 88(10):795-6.

14. Rezaeian, M. Age and sex suicide rates in the Eastern Mediterranean Region based on global burden of Disease estimates for 2000. East Mediterr Health J 2007: 13(4):953-60.

15. Rezaeian, M. Suicide/homicide ratios in countries of the Eastern Mediterranean Region. East Mediterr Health J 2008: 14(6): 1459-1465.

16. Rezaeian, M. Islam and suicide: a short personal communication. OMEGA 2008; 58(1):77-85.

17. Zhang J, Wang C. Factors in the Neighborhood as Risks of Suicide in Rural China: A Multilevel Analysis. Community Ment Health J 2011. [Epub ahead of print]

18. Fernando R, Hewagama M, Priyangika WD, Range S, Karunaratne S. Study of suicides reported to the Coroner in Colombo, Sri Lanka. Med Sci Law 2010; 50(1):25-8.

19. Zhang J, Conwell Y, Zhou L, Jiang C. Culture, risk factors and suicide in rural China: a psychological autopsy case control study. Acta Psychiatr Scand 2004; 110(6):430-7.

20. Kumar V. Burnt wives--a study of suicides. Burns 2003; 29(1):31-5.

21. Yip PS, Caine ED. Employment status and suicide: the complex relationships between changing 
unemployment rates and death rates. J Epidemiol Community Health 2011; 65(8):733-6.

22. Yur'yev A, Värnik A, Värnik P, Sisask M, Leppik L. Employment status influences suicide mortality in Europe. Int J Soc Psychiatry 2012; 58(1):62-8.

23. Crombie IK. Trends in suicide and unemployment in Scotland, 1976-1986. BMJ 1989; 298(6676): 782-4.

24. Platt S. Unemployment and suicidal behaviour: a review of the literature. Soc Sci Med 1984; 19(2): 93-115.

25. Hawkins EH. A tale of two systems: co-occurring mental health and substance abuse disorders treatment for adolescents. Annu Rev Psychol 2009; 60:197-227.

26. Legleye S, Beck F, Peretti-Watel P, Chau N, Firdion JM. Suicidal ideation among young French adults: association with occupation, family, sexual activity, personal background and drug use. J Affect Disord 2010; 123(1-3):108-115.

27. Aghilinegad M, Mohamadi S, Farshad AS. Effecting the Pesticides Consumption upon Agricultural Health. Journal Research of Shahid Beheshti University of Medical Science 2008; 31(4): 327-331. [Persian]

28. Kanchan T, Menezes RG, Kumar TS, Bakkannavar SM, Bukelo MJ, Sharma PS, et al. Toxicoepidemiology of fatal poisonings in Southern India. J Forensic Leg Med 2010;
17(6):344-7.

29. Ahmadi A, Pakravan N, Ghazizadeh Z. Pattern of acute food, drug, and chemical poisoning in Sari City, Northern Iran. Hum Exp Toxicol 2010; 29(9):731-8.

30. Shadnia S, Esmaily H, Sasanian G, Pajoumand A, Hassanian-Moghaddam H, Abdollahi M. Pattern of acute poisoning in Tehran-Iran in 2003. Hum Exp Toxicol 2007; 26(9):753-6.

31. Jia CX, Zhang J. Characteristics of young suicides by violent methods in rural China. J Forensic Sci 2011; 56(3):674-8.

32. Poeschla B, Combs H, Livingstone S, Romm S, Klein MB. Self-immolation: socioeconomic, cultural and psychiatric patterns. Burns 2011; 37(6):1049-57.

33. Campbell EA, Guiao IZ. Muslim culture and female self-immolation: implications for global women's health research and practice. Health Care Women Int 2004; 25(9):782-93.

34. Peck MD. Epidemiology of burns throughout the World. Part II: Intentional burns in adults. Burns 2012; 38(5):630-7.

35. Rezaeian, M. Epidemiology of self-immolation. Burns 2012. [In press]

36. Rezaeian, M. Sharifirad, G. Case fatality rates of different suicide methods within Ilam Province of Iran. Journal of Education and Health Promotion 2012. [In press] 